editor to be appointed by the executive". At the meeting the following officers were elected: President, Dr. A. Nicholls; Vice-President, Mr. J. Lake; Secretary-Treasurer, Dr. W. Williams. Further information and details of membership can be obtained from Dr. W. Williams, Department of Zoology and Comparative Physiology, Monash University, Box 92 P.O., Clayton, Victoria.

\section{Freedom in Science in the Nineteenth Century}

DR. J. R. BAKER's essay, "The Controversy on Freedom in Science in the Nineteenth Century", describing the debate between $\mathbf{E}$. Haeckel and $\mathbf{R}$. Virchow beginning at the Congress of German Naturalists and Physicians at Munich in Septem. ber 1877, which originally appeared in the volume of essays, The Logic of Personal Knowledge, presented to Prof. M. Polanyi on the occasion of his seventieth birthday, has now been issued by the Society for Freedom in Science as Occasional Pamphlet No. 22 (Pp. 13. Oxford: Assistant Secretary, Society for Freedom in Science, Department of Zoology, University Museum, 1962. 18.). Dr. Baker shows how radically this controversy differs from that which developed in the 1930 's and 1940's, and notes how it led to the exclusion of biology from the curricula of all senior classes in schools - a result which neither Haeckel nor Virchow could have foreseen and which both must have deplored. No one then had any intention of restricting the fredom of research workers to choose the subjects of their investigations, and, although it is not clear exactly what Virchow proposed, it is probable that he was concerned solely with the schools, where it is appropriate that instruction in science should be mainly factual.

\section{Idiopathic Clubbing of Fingers in the African}

From time to time Africans are admitted to medical wards with a gross degree of finger and toe clubbing; it is difficult to determine its cause. The clubbing is pronounced and cannot be missed, and, except for this, the patients enjoy good health. Similar cases occurring in other members of the family are not mentioned. On the other hand, clubbing is commonly met with in an African medical practice due to such diseases as chronic and sub-acute pulmonary disorders, notably bronchiectasis, lung abscess, bronchial carcinoma, empyema, silicotuberculosis and also, occasionally, in tuberculous disease of the lungs, when a bronchiectatic basis is a possible explanation. Heart disease also accounts for a number of cases including congenital lesions, sub-acute infective endocarditis and aneurysm of the aorta. Liver disease is often met with in the African, but Dr. Michael Gelfand, physician to the Harare Central Hospital, Salisbury, is not satisfied that this is a factor in its causation. Although steatorrhca is given as a cause, this is rarely seen in the African. The same causes of clubbing apply also to hypertrophic osteoarthropathy, in which an idiopathic variety has been described. Dr. Gelfand has not detected this and, in the Central African Journal of Medicine (8, No. 6; June 1962), a case of clubbing is described for which no possible explanation can be found.

\section{Conservation of Marshes, Bogs and other Wetlands}

Alarmed by the progressive loss of marshes, bogs and other wetlands through drainage and improvement' the Executive Board of the International
Union for Conservation of Nature and Natural Resources proposed early in 1961 that the Union, in close co-operation with the International Council for Bird Preservation and the International Wildfowl Research Bureau, should develop a programme on conservation and management of temperate marshes, bogs and other wetlands to be called 'Project MAR'. The final goals of the programme are to prepare a broad statement on the importance of marshes and wetlands to modern mankind and to give the widest publicity to this statement; to assemble all important data on means of conserving wetlands, to keep and improve them for wildlife through proper management, to restore them when debilitated and to make man-made aquatic habitats useful for wildlife; to make this information known and available to all those in a position to take action to advance the conservation of wetlands; to make an inventory and classification of all European and north-west African marshes, bogs and other wetlands of international importance and to offer technical assistance for the establishment of reserves in marshes, bogs and other wetlands classified as of international importance. The initial 'Project MAR' is described in an issue of the Bulletin of the International Union for Conservation of Nature and Natural Resources (New Series, No. 3; April-June 1962).

\section{Myxomatosis Survey}

D. A. Chapman, of Oundle School, has described investigations into myxomatosis (Oundle School Natural History Society, Annual Report 1961. Pp. ii +54. Oundle: Oundle School Natural History Society, 1962). The survey was begun after several rabbits with the disease had been noticed on a small stretch of road between Warmington and Morborne. Since then records have been made by many boys of the School and information collected from farmers and game-keepers within a five-mile radius of Oundle. The aim of the survey was to find the effect of the disease on the numbers of rabbits within this area. Chapman describes many observations on diseased rabbits. "In the later stages I have seen rabbits crouching in the grass with their ears folded backwards over their backs and the fur ruffled by the wind. They remain motionless for a long time like this. and I would not be surprised that if not interrupted they would stay like this until they die. Before the eyes have completely sealed over the rabbits still eat, but after this they lose their appetite." "Before the eyes sealed the diseased rabbits seemed to prefer to keep together, but once they close they lose each other and would scatter. I have never seen a diseased rabbit run into a burrow, and, where there is an infected warren, often the holes have not been kept clean, being semi-blocked by leaves and twigs. Whether the diseased rabbits go into burrows or are not allowed by the still healthy ones I do not know. In the advanced stages of the disease they sometimes take to wandering, and eventually die 11 to 18 days after infection." Nearly every farmer in the area affected north of Oundle pays a yearly membership to the Rabbit Clearance Society. The rabbit clearance worker, whose territory covers the north-west of the area, is fully employed and estimates that there are no more than about 70 rabbits in his small district. On February 8, ferrets were put into a set of warrens near Glapthorne Cow Pastures and only one rabbit was killed. Before myxomatosis had been found, three ferrets were put into the warren and 47 rabbits were shot in a morning. 